\title{
Original
}

\section{Mineralized Blood Vessels in the Capsules of Human Pineal Glands}

\author{
Tetsuo KodAKA ${ }^{1)}$, Ryoichi Mori ${ }^{2)}$, Hiromitsu EzUrE ${ }^{2)}$, \\ Junji ITO $^{3)}$ and Naruhito OtsukA ${ }^{2)}$
}

\begin{abstract}
We observed mineralized blood vessels in the capsules of human pineal glands containing abundant fibrous calcareous concretions in the capsules as well as non-fibrous calcareous concretions (brain sands) in the gland matrix. The capsular blood vessels were sometimes scattered with mineralized, round deposits of various sizes containing minute spherical deposits (MSD). The MSD showed hypermineralization similar to that in capsular fibrous concretions reported in our recent study and some MSD resembled those consistent with Fahr's disease. Occasionally, the vessel lumens were completely embedded with mineralized deposits. As the characteristic means of detection from the mineralized blood vessels, the volume of $\mathrm{Na}$ was significantly higher than that of the matrix non-fibrous concretions. The origin of $\mathrm{Na}$ in the mineralized blood vessels containing MSD was likely derived from the connective tissue fluid. Our findings suggested that a human pineal gland matrix containing numerous non-fibrous concretions is likely to associate with mineralized deposits within the blood vessels as well as fibrous concretions in the capsule.
\end{abstract}

Key words : human pineal capsule, mineralized blood vessel, minute spherical deposits (MSD), backscattered electron (BSE) imaging, energy-dispersive $\mathrm{X}$-ray $(\mathrm{EDX})$ microanalysis

\section{Introduction}

We previously reported no correlation between age and the masses of either pineal calcareous concretions (brain sands) or prostatic calculi in 40 human males ranging in age from 31 to 95 years ${ }^{1)}$. However, there was a low negative trend between aging and the mineralized volumes of the deposits by microradiography. We also recently observed fibrous calcareous concretions associated with characteristic minute spherical deposits (MSD) including a larger relative amount of $\mathrm{Na}$ as well as $\mathrm{Ca}$ and $\mathrm{P}$ in the capsule of a human pineal body and a large number of nonfibrous calcareous concretions in the matrix ${ }^{2)}$.

In the present study, we revealed occasional mineralized blood vessels in the capsules of adult human pineal glands by backscattered electron (BSE) imaging, and analyzed the elemental composition of these minute mineralized deposits in the vessel lumens by energy-dispersive X-ray (EDX) microanalysis in a scanning electron microscope (SEM).

\footnotetext{
1) Class of Anatomical-physiology, Musashigaoka College, 111-1 Minami-Yoshimi, Yoshimi-cho, Hiki-gun, Saitama 3550154, Japan.

2) Department of Anatomy, Showa University School of Medicine.

3) Department of Physical Therapeutics, Showa University School of Nursing and Rehabilitation Sciences.
} 


\section{Materials and Methods}

Human pineal glands were extracted from 40 deceased adult males, who had previously agreed to donate their bodies for medical research, during the routine dissection course in 1996 to 1998 at Showa University School of Dentistry ${ }^{1)}$. In this study, we further examined 11 of the 15 pineal bodies used in our recent study ${ }^{2}$.

Seven pineal glands were dehydrated with ethanol for embedding in polyester resin. The samples were sectioned sagittally with a diamond wheel and then ground with grinding stones to yield slices of approximately $200 \mu \mathrm{m}$ in thickness. Contact microradiographs of the sections were obtained. The ground surfaces were finally polished with 5- and $0.3-\mu \mathrm{m}$ alumina on polishing cloths, and then ultrasonically cleaned for examination by transmitted-light brightfield or differential interference contrast (DIC) microscopy (Nikon, Tokyo, Japan).

The ground surfaces of pineal glands were also observed after carbon coating by composite BSE imaging with a SEM (S-2500CX; Hitachi, Tokyo, Japan) operated at $20 \mathrm{kV}$. Masses showing a BSE signal in the pineal capsule regions were analyzed qualitatively and quantitatively using an EDX detection system (delta-4; Kevex, CA, USA), with an accelerating voltage of $15 \mathrm{kV}$, a specimen irradiation current of $1 \times 10^{-7} \mathrm{~mA}$, and a beam spot of $15 \mathrm{~nm}$. Each mass showing a BSE signal was analyzed at 20 points $(n=20)$ and the means $( \pm$ SD) calculated.

Four of the remaining resin-free pineal glands were cut sagitally into several slices with a diamond knife, dehydrated with ethanol, and then dried at the critical point of $\mathrm{CO}_{2}$. The composite BSE images of the cut surfaces of pineal grounds were also viewed after carbon coating by SEM operated at 15 or $20 \mathrm{kV}$. In addition, it is reported that the areas possessing metallic elements such as $\mathrm{C}, \mathrm{P}$, and $\mathrm{Na}$ in biological materials show higher BSE signals in the uneven planes of natural surfaces ${ }^{3)}$ and fractured surfaces ${ }^{4)}$, as well as in the ground smooth planes $^{5,6)}$.

\section{Results}

The cut surfaces of a resin-free pineal capsule showed occasional, high BSE signals in longitudinally arranged blood vessels, although the majority of vessels showed little or no BSE signal (Fig. 1a). Higher magnification of the same area revealed broad bands of high BSE signal concentrically surrounding the mineralized vessels (Fig. 1b).

Fig. 2 shows the smooth surface of the resin-embedded and ground sections of pineal capsules containing blood vessels. The brightfield imaging of a blood vessel that was ground transversely and longitudinally (Fig. 2a) was consistent with composite BSE imaging of the same region (Fig. 2b). The blood vessel wall showed mineralized, round areas containing minute spherical deposits (MSD) attached to each other. These variously sized deposits showed relatively high BSE signals. Some MSD were also present in the blood vessel lumens (Fig. 2b).

The DIC view of two smaller blood vessels (Fig. 2c, e) and the corresponding composite BSE images (Fig. 2d, f) of the oblique-transverse, smooth ground surfaces are also shown. These respective images of the same regions highlight two circular blood vessel lumens at the cut 


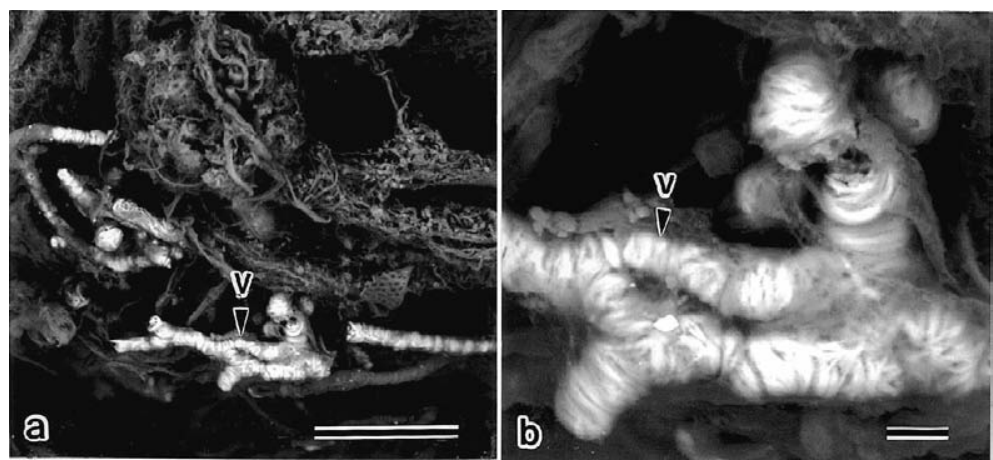

Fig. 1. Mineralized blood vessels (V) in a pineal capsule. BSE images of blood vessels showing relatively high signals in the resinfree sample. a, b Bars, $100 \mu \mathrm{m}$.
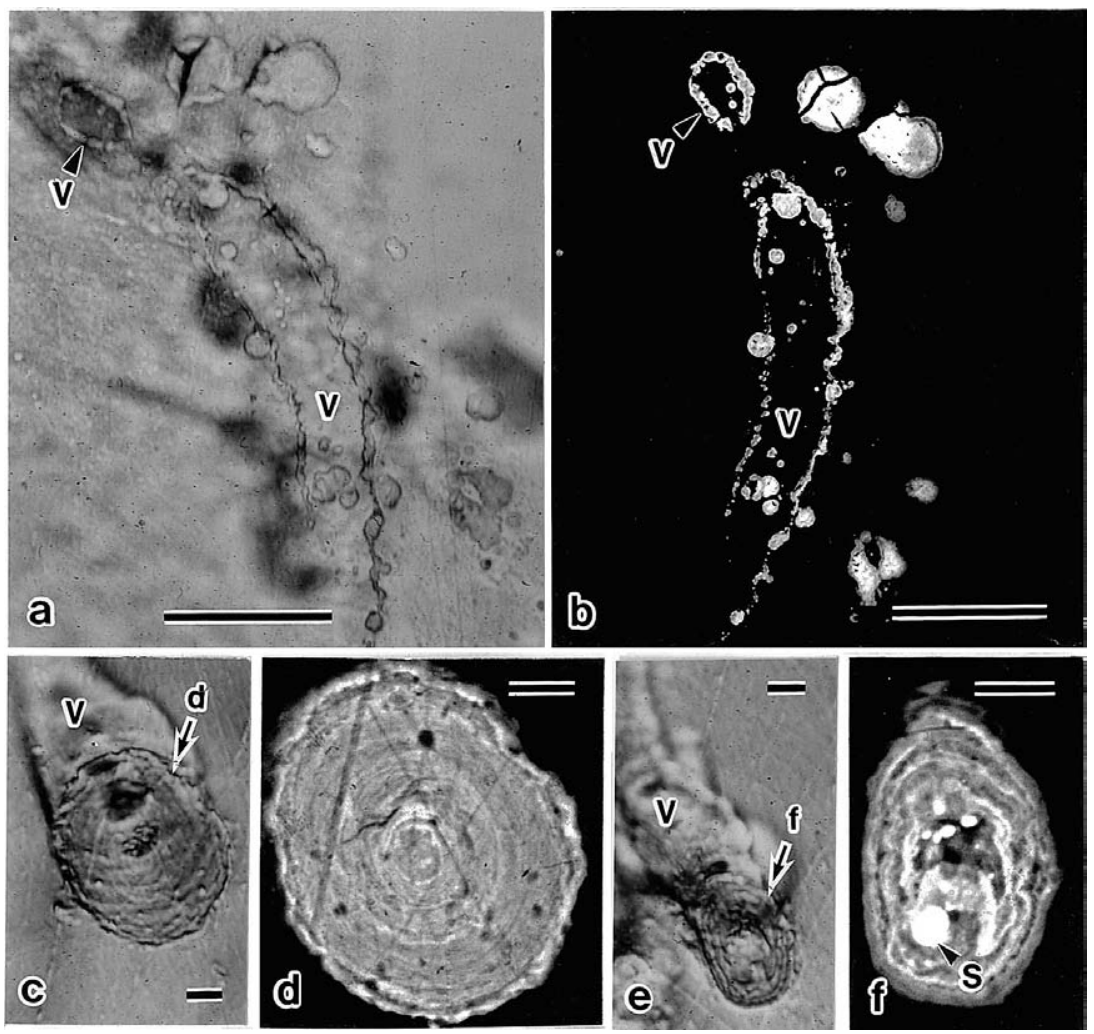

Fig. 2. Ground sections of pineal glands embedded in resin. (a) Brightfield view, (c, e) DIC view, (b, d, f) BSE images. Fig. 2 (a, b), 2 (c, d), and $2(\mathrm{e}, \mathrm{f})$ show the same mineralized blood vessel $(\mathrm{V})$, respectively. The blood vessel walls sectioned transversely and longitudinally are formed with round-shaped deposits in varied small sizes containing minute spherical deposits. The arrow with (d) in Fig. $2 \mathrm{c}$ and the arrow with (f) in Fig. 2e show the BSE images of Fig. $2 \mathrm{~d}$ and $2 \mathrm{f}$, respectively. S (arrowhead in Fig. 2f), minute spherical deposits (MSD) showing high BSE signals. a, b Bars, $100 \mu \mathrm{m}$; c-f Bars, $10 \mu \mathrm{m}$. 
Table 1. Amounts of $\mathrm{Ca}, \mathrm{P}$, and $\mathrm{Na}$ (weight $\%$ ), and $\mathrm{Ca} / \mathrm{P}$ (molar ratio) in the minute mineralized deposits within blood vessel lumens measured approximately $15-\mu \mathrm{m}$ in diameter. SEM-EDX microanalysis of the whole area with relatively high BSE signals.

\begin{tabular}{cc}
\hline Mineralized deposits & Whole \\
\hline $\mathrm{Ca}$ & $9.00 \pm 1.79$ \\
$\mathrm{P}$ & $5.14 \pm 1.25$ \\
$\mathrm{Na}$ & $1.80 \pm 0.41$ \\
$\mathrm{Ca} / \mathrm{P}$ & $1.35 \pm 0.27$ \\
\hline
\end{tabular}

Mean \pm SD

$\mathrm{Ca}, \mathrm{P}$, and $\mathrm{Na}$ : \% by weight $; \mathrm{Ca} / \mathrm{P}$ : molar ratio

surfaces that were entirely embedded with the relatively high BSE-signaled materials showing slight and rough concentric rings, with one vessel MSD showing higher BSE signals than the other.

SEM-EDX microanalysis identified $\mathrm{Ca}$ and $\mathrm{P}$ as major elements and $\mathrm{Na}$ as a larger relative amount element in the mineralized blood vessels showing BSE signals on the resin-embedded ground samples. $\mathrm{Mg}, \mathrm{S}, \mathrm{Cl}, \mathrm{K}, \mathrm{Al}$, and $\mathrm{Si}$ were also detected as trace elements.

Table 1 lists the amounts of $\mathrm{Ca}, \mathrm{P}$, and $\mathrm{Na}$ (by weight \%), and the $\mathrm{Ca} / \mathrm{P}$ molar ratio in the blood vessel lumens filled entirely with mineralized materials of approximately $15-\mu \mathrm{m}$ in diameter (for examples; see Fig. 2d, f) in human pineal capsules.

\section{Discussion}

In this study, we observed and analyzed the abundant calcareous concretions in the pineal body of adult male subjects ${ }^{1,2)}$, who also had some prostatic calculi; we and found mineralized deposits occasionally dispersed within blood vessels in the pineal capsule containing a larger relative amount of fibrous calcareous concrations ${ }^{2)}$. Analysis of $\mathrm{Ca} / \mathrm{P}$ molar ratios (Table 1) in these glands suggested that the mineralized deposits might represent the successional change from amorphous calcium phosphate towards hydroxyapatite, similar to the matrix concretions reported previously ${ }^{7-9)}$. Similarly, $\mathrm{Kim}^{10)}$ reported the presence of calcium hydroxyapatite in a calcified human aortic valve and media. The present study also revealed that fibrous calcareous concretions in the human pineal capsule contained a significantly higher amount of $\mathrm{Na}$ than the non-fibrous calcareous concretions ${ }^{2)}$. We propose that this difference reflected that some $\mathrm{Na}$ ions in the mineralized blood vessels may be taken up as $\mathrm{Na}$ - and $\mathrm{CO}_{3}$-containing apatite ${ }^{11)}$, similar to that in the fibrous capsule concretions reported previously ${ }^{2)}$.

In our previous study ${ }^{2)}$, the pineal gland capsular concretions showed variable amounts of fibrous globular structures that could represent the calcification of cell remnants or matrix vesicles $^{11-14)}$. In this scenario, some of the cell remnants might become the minute spherical deposits (MSD) showing hyper mineralization ${ }^{2)}$ observed herein. 
In the pineal capsule, the mineralized round-shaped deposits of varying, but small, sizes, which were observed in the longitudinal and transverse ground planes of blood vessels, were similar to those noted in Fahr's disease patients ${ }^{15)}$. However, the three-dimensional BSE images of blood vessels taken in this study showed the position of the mineralized deposits generally consistent with the circular arrangement of smooth muscle cells in the media walls. In addition, the smooth muscle cells of aortic ${ }^{14)}$ or arterial walls ${ }^{15)}$ are calcified in several diseases as well as the collagen fibers of connective tissues ${ }^{11,16-18)}$ and the collagen and elastic fibers of aortic or arterial walls $^{18)}$.

We have found no histopathological reports of blood vessel lumens entirely filled with mineralized deposits, except for brushite within the blood vessels of human primary molars ${ }^{19)}$ and a cow tooth ${ }^{20)}$, although mineralized plaque fragments scattered within vessel lumens have been reported in arteriosclerosis ${ }^{21-23)}$. Transverse planes of the vascular lumens showing mineralized deposits in this study resembled the capsular concretions with their rough concentric laminations. The peripheral substances might be smooth muscle cells, collagen and elastic fibers, and/or amorphous organic plaques that have been mineralized ${ }^{11,16-18)}$, whereas the blood vessel lumens filled with mineralized deposits may result from the calcification of organic contents such as plaque when a patient is affected by atherosclerosis or thrombosis ${ }^{21-24)}$. Regrettably, we could not determine a clear relationship between the MSD showing a hyper-mineralization and the smaller mineralized round-shaped deposits attached to the blood vessels, as shown in Fig. 2 (b, d, f).

Previously ${ }^{1}$, we reported a low negative correlation $(\mathrm{r}=-0.39, P<0.05)$ between the masses of pineal calcareous concretions and prostatic calculi in human adult males. In this study, we used similar pineal glands containing numerous calcareous concretions from male subjects who had a low amount of prostatic calculi. These pineal glands also contained mineralized blood vessels as seen in Fahr's disease ${ }^{15)}$, and many capsular concretions. Therefore, in a human pineal gland susceptible to mineralization, a process is most likely to occur in the connective tissue capsule $^{12-16)}$ of the gland as well as in the matrix ${ }^{11,12,14)}$.

\section{Acknowledgements}

We are grateful to Dr. Tsuneyoshi Sano, for his kind cooperation. We also acknowledge the 11 adult deceased males who donated their organs for studies such as this.

\section{Conflict of interest}

The authors have declared no conflict of interest.

\section{References}

1) Mori R, Kodaka T, Sano T. Preliminary report on the correlations among pineal concretions, prostatic calculi and age in human adult males. Anat Sci Int. 2003;78:181-184.

2) Kodaka T, Mori R, Ezure H, et al. Fibrous calcareous concretions in the capsules of human pineal glands. Showa Univ J Med Sci. 2013;25:223-231.

3) Kodaka T, Hirayama A, Sano T, et al. Fine structure and mineral components of primary calculi in some human 
prostates. J Electron Microsc. 2008;57:133-141.

4) Kodaka T, Sano T, Nakagawa K, et al. Structural and analytical comparison of gallbladder stones collected from a single patient: studies of five cases. Med Electron Microsc. 2004;37:130-140.

5) Kodaka T, Mori R, Debari K, et al. Scanning electron microscopy and electron probe microanalysis studies of human pineal concretions. J Electron Microsc. 1994;43:307-317.

6) Kodaka T, Sano T, Mori R. Scanning electron microscopy subsequent to a combined treatment of $\mathrm{NaOCl}$ and EDTA in some non-collagenous calcified matrixes. J Electron Microsc. 2000;49:195-202.

7) Mabie CP, Wallace BM. Optical, physical and chemical properties of pineal gland calcifications. Calcif Tissue Res. 1974;16:59-71.

8) Bocchi G, Valdre G. Physical, chemical, and mineralogical characterization of carbonate-hydroxyapatite concretions of the human pineal gland. J Inorg Biochem. 1993;49:209-220.

9) Humbert W, Pevet P. Calcium concretions in the pineal gland of aged rats: an ultrastructural and microanalytical study of their biogenesis. Cell Tissue Res. 1995;279:565-573.

10) Kim KM. Calcification of matrix vesicles in human aortic valve and aortic media. Fed Proc. 1976;35:156-162.

11) Kodaka T, Mori R, Hirayama A, et al. Fine structure and mineral components of fibrous stonelike masses obtained from the human mesenteries. Med Electron Microsc. 2003;36:272-281.

12) Kubota T, Hirano A, Yamamoto S, et al. The fine structure of psammoma bodies in meningocytic whorls. $J$ Neuropathol Exp Neurol. 1984;43:37-44.

13) Kubota T, Sato K, Yamamoto $\mathrm{S}$, et al. Ultrastrucural study of the formation of psammoma bodies in fibroblastic melningioma. J Neurosurg. 1984;60:512-517.

14) Christoffersen J, Landis WJ. A contribution with review to the description of mineralization of bone and other calcified tissues in vivo. Anat Rec. 1991;230:435-450.

15) Guseo A, Boldizsar F, Gellert M. Elektoronenoptische untersuchungen bei "striato-dentaler Calcifikation" (Fahr). Acta Neuropathol. 1975;31:305-313.

16) Humbert W, Cuisinier F, Voegel JC, et al. A possible role of collagen fibrils in the process of calcification observed in the capsule of the pineal gland in aging rats. Cell Tissue Res. 1997;288:435-439.

17) Driessens FCM. Mineral aspects of dentistry. Basel: Karger; 1982. (Monographs in oral science; 10).

18) Anderson KA, Burbach JA, Fenton LJ, et al. Idiopathic arterial calcification of infancy in newborn siblings with unusual light and electron microscopic manifestations. Arch Pathol Lab Med. 1985;109:838-842.

19) Arys A, Jedwab J, Pireaux JJ, et al. Brushite in the pulp of primary molars. J Oral Pathol Med. 1989;18:371-376.

20) Kodaka T, Hirayama A, Mori R, et al. Spherulitic brushite stones in the dental pulp of a cow. J Electron Microsc. 1998;47:57-65.

21) Sarig S, Weiss TA, Katz I, et al. Detection of cholesterol associated with calcium mineral using confocal fluorescence microscopy. Lab Invest. 1994;71:782-787.

22) Topoleski LD, Salunke NV, Humphrey JD, et al. Composition- and history-dependent radial compressive behavior of human atherosclerotic plaque. J Biomed Mater Res. 1997;35:117-127.

23) Schwarz U, Buzello M, Ritz E, et al. Morphology of coronary artherosclerotic lesions in patients with end-stage renal failure. Nephrol Dial Transplant. 2000;15:218-223.

24) Verstraete M. Coronary atherosclerosis and thrombosis. Recenti Prog Med. 1990;81:221-227.

[Received April 30, 2013 : Accepted May 21, 2013] 